\title{
Como a Mente se Torna Social para Barbara Rogoff? A Questão da Centralidade do Sujeito
}

\author{
EvelineVieira Costa ${ }^{1}$ \\ Maria C.D.P. Lyra ${ }^{2}$ \\ UniversidadeFederaldePemambuco
}

\begin{abstract}
Resumo
Partindo de uma perspectiva sociocultural que fundamenta uma Psicologia Cultural na qual a mente é concebida como social desde o nascimento, este trabalho procura resgatar a autonomia do sujeito inserido na atividade sociocultural. Visando tal objetivo, elabora uma síntese entre a unidade de análise proposta por Barbara Rogoff (que inclui os sujeitos, as relações intersubjetivas e a comunidade/instituição na qual as atividades socioculturais têm lugar) e a perspectiva de Jaan Valsiner acerca da autonomia de um sujeito semiótico. São analisadas as contribuições de Rogoff, particularmente os conceitos de participação guiada e apropriação participatónia, e as idéias de Valsiner acerca da separação inclusiva e do ato criativo do sujeito em um tempo irreversível. A síntese proposta delineia um sujeito imerso na atividade sociocultural, mas capaz de pensar sobre ela, mudá-la e aprimorá-la, resgatado, assim, em sua autonomia através da sua caractenística de sujeito semiótico.

Palavras-chave: Perspectiva sociocultural; psicologia cultural; atividade sociocultural; autonomia do sujeito.
\end{abstract}

\section{How the Mind Comes to be Social to Barbara Rogoff? The Question of the Centrality of the Person}

\begin{abstract}
This essay aims to ransom the autonomy of subject into sociocultural activity. It starts discussing the sociocultural perspective of Cultural Psychology where mind is conceived as a social entity developing in a social world. To achieve this objective we use the unity of analysis as sociocultural activity proposed by Barbara Rogoff, including the subjects, the relationship between them and the institutions and community in which this activity takes place. Here is highlighted her concepts of guided participation and participatory appropriation. In the same way, we make use of Jaan Valsiner's notion of inclusive separation to emphasize the semiotic capacity the subjects show in creative acts in a reversible time. The synthesis appears when this subject is not only approached as immersed in an activity, but as subject of that activity, emerging through the capacity to think about and change it, developing the autonomy through the semiotic capacity of human being.

Keywords: Sociocultural perspective; cultural psychology; sociocultural activity and the autonomy of the subject.
\end{abstract}

Duas linhas teóricas e metodológicas atuais na Psicologia, sobretudo na Psicologia do Desenvolvimento, encontram sua diferença no fato da mente ser ou não considerada social ao nascer. Para aqueles que não a consideram social desde o nascimento, o foco de análise e compreensão está nas estruturas mentais do indivíduo construídasatravés das interações constantes com o meio - físico e social - durante o desenvolvimento. Como representando esta vertente, pode-se destacar a teonia proposta porJean Piaget, principalmente na consideração acenca da emergência da mente humana e de seu desenvolvimento (Piaget, 1964, 1971; Piaget \& Inhelder, 1966).

Piagetvê a mente da criança ao nascercomo uma mente egocêntrica. Trata-se de uma caractenística dominante da

\footnotetext{
${ }^{1}$ Endereço para comespondência: Rua Paula Batista, 565, 52070-070. Recife, PE. Fones: (81) 3304.1311/9989.3307. E-mail: eveline_costa@br.inter.net
}

mente da criança, desde o nascimento, e que se manifesta nas primeirasmanifestações eusos dalinguagem considerada como atos ainda não sociais, mas voltados para a própria criança. Nesta abordagem, existe, claramente, uma primazia do sujeito (existe primeiro) em relação às trocas sociais e ao ambiente cultural. Abordagens como estas podem ser chamadasdeabordagemdainfluênciasocialou cultural(Chavajay \& Rogoff, 2002; Rogoff, 1990, 1998) ou, simplesmente, “cognition plus" (Lave, 1991).

Poroutro lado, encontram-se as abordagens socioculturais ou sociohistóricasque consideramamente humanacomo social e cultural desde o nascimento. Trata-se de um conjunto de idéias que, nascidas a partir da forte influência das concepções de Vygotsky $(1978,1987,2001)$, compõem o cerne da Psicologia Cultural (Bruner, 1990; Valsiner, 1995). Nesta perspectiva, todo ato da criança é concebido como ocorrendo em um ambiente típico da espécie humana que é culturalmente construído através da históna da humanidade (Tomasello, 1999). Desta forma, podese dizer que desde o nascimento as manifestações da 
criança são direcionadas a um Outro (social). Assim, as primeiras manifestações da linguagem na criança não são consideradas como manifestações de uma mente egocêntrica mas como atos de comunicação (Vygotsky, 1978, 1987, 2001). Nesta abordagem, é papel da interação social não só permitir o desenvolvimento e sofisticação desta mente (postulado aceito pela primeira abordagem), mas é, ela própria (a interação social), constitutiva deste desenvolvimento e dos processos mentais que se desenvolvem ao longo do tempo.

Este trabalho se insere na segunda vertente acima referida e se detém, particularmente, na contribuição de Barbara Rogoff à Psicologia Cultural. A abordagem sociocultural de Rogoff focaliza a atividade sociocultural como unidade de análise. Esta unidade de análise inclui os sujeitos, as relações intersubjetivas e a comunidade/ instituição na qual estas atividades têm lugar, compondo três elementos intrinsecamente relacionados e que são, segundo a autora, impossíveis de serem compreendidos separadamente (Rogoff, 1990, 1995, 1998). Esta abordagem diferencia-se radicalmente da abordagem da influência cultural na qual a unidade de análise recai sobre o sujeito, muito embora considere que este sujeito esteja aberto ao meio ambiente, recebendo deste o alimento para desenvolver-se. Para Rogoff, o sujeito não vem primeiro, tampouco as relações sociais e a cultura. Ao contrário, o sujeito e a cultura são vistos em estado de desenvolvimento constante, dinamicamente relacionados, de maneira que nem o sujeito pode servisto em separado, nem as relações sociais e a cultura.

Na concepção desta autora, a cultura compreendida tanto como interações intersubjetivas, quanto por interações com os artefatos culturais, simbólicos e materiais, é constitutiva da mente humana. Mais ainda, esta cultura não permite apenasa mente desenvolver-se, construindo estruturas e processos mentais (resultantes das interações com o meio social e cultural) para tomarse uma mente social, como nos propõe a abordagem da influência social ou cultural. A cultura, para Rogoff, é constitutiva do desenvolvimento desta mente já social ao nascer. O sujeito passa a serum elemento tão importante quanto as relações produzidas entre sujeitos e a cultura. A cultura os constitui e ambos são constituídos pelas relações nas quais o sujeito é parte ativa. Os três elementos estão relacionados de maneira tal que se toma impossível a caractenzação autônoma de qualquer um deles.

Todavia, apesarda abrangênciainovativa da contribuição de Rogoff, a centralidade e singularidade do sujeito psicológico, na concepção desta autora, é, de certa forma, deixada de lado. Sobretudo considerando os processos de sociogêneseinerentesao conceito deapropriação dospadrões culturais de comportamento, através de diferentes modelos de participação guiada (Rogoff \& Toma, 1997), a proposta de Rogoff sugere que o pólo diferenciado da subjetividade (individual) surge em decorrência da fusão com o ambiente cultural (Lyra \& Valsiner, 1998). É justamente em relação a este aspecto que a proposta de Jaan Valsiner acerca do desenvolvimento sociocultural da criança (presente, também, em toda a sua concepção de Psicologia Cultural) procura trazer a singularidade do sujeito humano, ao mesmo tempo em que este sujeito está indissociavelmente relacionado às relações sociais e culturais que o cercam (Valsiner 1997, 2000).

A questão que se coloca é o resgate da autonomia deste ser imerso nas contingências de um aparato social. A abordagem co-construcionista de Valsinerconsidera tanto o sujeito singular, quanto este aparato, simultaneamente. Ele reclama não apenas o caráterinclusivo do sujeito na cultura, desenvolvendo sua autonomia através de uma dinâmica de trocas chamada de separaçãoinclusiva (Valsiner, 1997, 2000; Valsiner \& Van DerVeer, 2000). Concebe o sujeito, desta forma, em um processo incontestável de imersão e relação, mas existindo como realidade axiomática, ou seja, no-seulugar-no-mundo. É este lugar-no-mundo que implica na diferenciação entre o sujeito e a cultura. Procurando responderà pergunta 'ondeestá osujeitonesta redederelações', a perspectiva proposta porValsinerinveste-se a favordo 'resgate do sujeito', fazendo-o reaparecerem meio ao emaranhado das relações sociais e da imersão na cultura.

A partir da ênfase no estudo das capacidades e caracteństicas do funcionamento semiótico do sujeito, este autor procura recuperar a identidade e a tarefa de uma Psicologia Cultural, na qual o sujeito e a cultura são, ao mesmo tempo, interdependentes e distintos (Valsiner, 1997, 2000).

O objetivo deste trabalho é explicitara contribuição destes dois teónicos pertencentes a abordagem sociocultural Rogoffe Valsiner-, procurando chegara uma síntese que integre a singularidade do sujeito na imersão deste sujeito em relações sociais e culturais. Trata-se de esclarecer que, se porum lado, o sujeito está imerso na cultura, poroutro, este sujeito não é apenas um elemento na atividade sociocultural, mas o elemento por excelência, porque é capaz de emergir desta como um ser que pensa sobre ela, utilizando-se dos mesmos instrumentos socioculturais que o constituem e, ao mesmo tempo, o mantém inseparavelmente relacionado à cultura (Ex.: a linguagem). Através da capacidade semiótica, que possibilita abstrair e analisar a atividade do sujeito nas suas relações com a cultura, toma-se possível, também, a sofisticação dos próprios instrumentos culturais que constituem a atividade do sujeito. Desta forma, o sujeito é o elemento transfomador, constitutivo e enredado na própria cultura. 


\section{AContribuição de Barbara Rogoff}

Os dois grandes nomes da abordagem da 'influência social ou cultural' e da teonia sociocultural dignos de nota são Piagete Vygotsky. A teoria de Piaget propõe como unidade de análise o indivíduo como construtor de suas estruturas mentais ${ }^{2}$ (Piaget, 1971). Por outro lado, a perspectiva de Vygotsky enfatiza como o mundo das relações sociais e culturais é constitutivo da mente humana (Vygotsky, 2001).

Como Piaget e Vygotsky partiram de diferentes perspectivas, é difícil meramente recorrer a uma complementaridade entre ambos sem cairem contradições inerentes às perspectivas de sentidos opostos com as quais trabalharam (ver Bnuner, 1997 e Lerman, 1996, para uma análise detalhada desta questão). Os diferentes focosde análise utilizados pelos dois podem explicaralgumas diferenças de opiniõesentre eles. Considerando o meio social, Piagetestava interessado na mudança de perspectiva da criança e nas estruturas intelectuais do sujeito, enquanto Vygotsky, no desenvolvimento dos processose funções mentais supeniores e no uso de símbolos e signos. Como conseqüência, a fase sensível à influência social situa-se em tomo dos 7 aos 12 anos para Piaget (1964, 1971; Piaget \& Inhelder, 1966), enquanto para Vygotsky $(1978,1987,2001)$, a criança é, desde o nascimento, um serimerso em trocas sociais que são constitutivas da sua mente. Quando se tenta analisar o papel do indivíduo e do meio social para a formação da mente humana, concebendo-os como entidades ontologicamente distintas, é preciso advogaruma terceira entidade, que é a interação, a fim de relacionar estas entidades autônomas, mesmo que se proponha uma relação interacional dinâmica dos elementos que a compõe (Rogoff, 1990).

A 'abordagem da influência social ou cultural' (Chavajay \& Rogoff, 2002; Rogoff, 1998) é justamente aquela que considera a mente como não social ao nascer e que tem como unidade de análise o sujeito, mesmo que este sujeito esteja aberto à influência do meio social e cultural. Neste perspectiva, o sujeito é concebido como um sistema auto-suficiente e autônomo em relação à cultura, embora ativo e aberto ao meio.

O contraste desta perspectiva com a proposta sociocultural de Rogoff está no foco de análise que recai no meio social e cultural como fator indispensável e constituinte de um sujeito que mantém uma relação de mútua constituição com este meio. Segundo Rogoff, precisa-se de uma unidade de análise que não privilegie

\footnotetext{
${ }^{2}$ O relacional para Piaget (1971) mantém a ênfase no indivíduo como unidade de análise, o que se enquadra naquilo que Rogoff (1990) chamou de 'abordagem da influência social ou cultural'.
}

nem o sujeito, nem o meio social e cultural, ou seja, uma unidade de análise que mantenha a função de um sistema indivisível que represente o todo que se quer analisar, tal como ressalta Vygotsky: "A unidade é uma parte vital e imedutível do todo." (Vygotsky, 1987, p. 46).

Na direção do que Rogoff propõe, Cole e Wertsch (1996) argumentam em prol de uma unidade de análise que possibilite estudara mente humana como constituída noe pelo ambiente social e cultural. Visando tal objetivo, os refenidos autores apresentam um exemplo (transcrito a seguir), utilizado por Bateson (1972), no qual é discutido o limite físico da mente humana, ou seja, a impossibilidade do sujeito serconsiderado como uma entidade separada dos artefatos mateniais e simbólico-culturais que o constituem.

... suponha que eu seja um homem cego e use uma bengala. Eu vou andando passo por passo... Onde eu começo?É o meu sistema mental limitado pela minha mão segurando a bengala?É limitado pela minha pele? Começa na metade da bengala?Começa na ponta da bengala?(Bateson, 1972, p.459) ${ }^{3}$

Na mesma direção, Wertsch (1998) exemplifica a condição cultural humana a partir de um exemplo onde mostra que um simples ato de multiplicação, utilizando a norma algorítmica escolar, pode significar a única condição da resolução do problema, muito embora outras estratégias algońtmicas possam ser usadas para a resolução dos mesmos problemas (Carraher, Carraher \& Schliemann, 1985). Esta mente não pode ser entendida a não ser em relação à norma algorítmica que foi empregada na resolução do problema escolar. $\mathrm{O}$ algonitmo utilizado, que é um artefato cultural-simbólico, torna-se parte constitutiva do funcionamento mental daquele que dele faz uso (Wertsch, 1998).

Três aspectos da proposta de Rogoff são fundamentais para que se compreenda a sua contribuição à perspectiva sociocultural: a unidade de análise proposta, o processo de apropriação e a metodologia por ela utilizada nos trabalhos empínicos.

\section{A unidade de análise}

Éimportante explicitarque o contexto social é entendido por Rogoff como constituído por "instituições, normas e práticas desenvolvidas e apropriadas pelas gerações passadas" (Rogoff, 1990, p. 138). Estas gerações passadas mudam a histónia cultural do curso do desenvolvimento e

\footnotetext{
${ }^{3}$ Todas as traduções apresentadas neste trabalho foram realizadas pela primeira autora de forma livre, mas procurando guardar o sentido do enunciado original.
} 
deixam "um legado para o indivíduo em forma de tecnologias, tais como o letramento, o sistema numérico e computadores, tanto quanto os sistemas de valores, "scripts" e nomas para lidar com as situações encontradas pelo indivíduo" (Rogoff, 1998, p. 682).

Para explicar a relação dos indivíduos com as pessoas mais experientes, a autora criou o conceito de participação guiada. Este sugere a participação ativa da pessoa em se beneficiar da direção social, bem como, a necessidade da compreensão desta ajuda e o papel desempenhado no que diz respeito à formação da mente da criança (Rogoff, 1990). A participaçãoguiada remete às bases sobre as quais se fundamenta a intersubjetividade. A criança nasce equipada com a capacidade de compartilhar significados? $\mathrm{Ou}$, pelo contrário, o significado é algo que é posto à criança, a partir da interpretação do adulto sobre as suas ações?

Definindo a intersubjetividade, a autora comenta:

Embora a intersubjetividade tenha sido definida de vánias maneiras, ela remete o foco de atenção à maneira como a pessoaé envolvidanum trabalho conjunto, que pode ocomer como resultado de uma compreensão mútua da situação, que permite o envolvimento interpessoal. (Rogoff \& Toma, 1997, p. 472)

Para Rogoff (1990), a criança nasce equipada com esta capacidade de compartilhar significados através da capacidade de compreensão mútua pois, do contrário, senia preciso explicaro aparecimento da intersubjetividade como vinda do 'nada'. Portanto, entendendo que a criança nasce com esta capacidade, resta a explicar o seu desenvolvimento (da intersubjetividade) e o seu aprimoramento nas relações sociais que são constitutivas dos processos mentais da mente da criança.

Para Rogoff (1990, 1991, 1995, 1998; Rogoff \& Toma, 1997; Rogoff, Topping, Baker-Sennett, \& Lacasa, no prelo), a intersubjetividade se estabelece numa atividade sociocultural que assume o caráterde unidadedeanálisepara a autora. Esta atividade sociocultural precisa serabarcada como um 'todo' indivisível (Vygotsky, 1987), no qual se inserem o sujeito, as relações interpessoais, os artefatos culturais e a comunidade/instituição.

Para estudar este 'todo', Rogoff (1995) estabelece a estratégia metodológica de planosdeanálise (individual, interpessoal e comunitário/institucional), também chamado de focos deanálise, para contrastar com níveis de análise "que trata o pessoal, o interpessoal e o processo comunitánio como entidades separadas, antes que simples distinções analíticas" (Rogoff, 1998, p. 688). A autora (Rogoff \& cols., no prelo) explicita que o foco pessoal analisa a mudança individual; o foco interpessoal, as contribuições que ocorrem como decorrência da comunicação entre pares; o foco comunitário, as contribuições das tradiçõesinstitucionaise dosinstrumentos culturais.

Cada foco deanáliseé realçado e detalhado "enquanto os outros permanecem menos detalhados em background, para simplificara análise de uma linha particularde estudo" (Rogoff \& cols., no prelo, p. 8). Cada linha de estudo, ou disciplina científica, é considerada como 'figura', enquanto as outras são consideradas como 'fundo', levando a uma relação advinda de ambos, necessánia para a compreensão do fenômeno.

A questão que se apresenta é como o sujeito em interação numa atividade sociocultural se beneficia desta interação para se desenvolvera partirda participação guiada. Em outras palavras, como a mente se desenvolve socialmente nesta interação, na qual ocorre a participação guiada?Para explicar esta questão, a autora lançará mão do conceito de apropriação, contrastando-o ao de "intemalização", que será explorado a seguir.

\section{Internalização versus apropriação}

Segundo Rogoff (1995), a concepção de Vygosky acerca do processo de intemalização da atividade social envolve uma separação entre o indivíduo e o meio social que se evidencia na separação temporal existente entre as relações inter-individual e a constituição das capacidades intra-individuais do sujeito. A autora em pauta comenta:

... a caracterização de Vygotsky sobre a intemalização como proveniente do interpessoal para o intrapessoal envolve uma separação no tempo dos aspectos sociais e individuais da atividade, a qual está em desacordo com minha idéia de apropriação participatónia, na qual, a participação de alguém é de uma só vez um processo social e individual. (Rogoff, 1995, p. 161, nota de rodapé)

Assim, o conceito de intemalização implica numa separação entre o indivíduo e o meio social. Isto ocorre porque este conceito exige uma delimitação temporal entre um 'antes', inter-individual (asrelações que oconem entre os indivíduos no meio social), e um 'depois', intraindividual (as capacidades e processos intrasubjetivos).

A autora propõe então o conceito de apropriação como um processo de participação na atividade social e não como o resultado desta participação. Esta concepção de que a intemalização é resultado ('depois') da participação dos indivíduos nas atividades sociais ('antes') pode conduzira uma separação entre o intemo e o extemo. Para Rogoff (1990), o que subjaz à concepção de intemalização 
é a imposição de um limite entre a mente individual e o mundo social extemo. Na análise de um discurso, por exemplo, onde temina a minha idéia e começa a sua?A autora comenta sobre esta impossibilidade de estabelecer limites da seguinte maneira:

Para agir e comunicar, os indivíduos são constantemente envolvidos numa troca que mistura o 'intemo' e o 'extemo' - trocas caracterizadas através do compartilhamento de significados entre osindivíduos. Os limites' entre as pessoas que estão em comunicação é sempre penetrado; é impossível dizer'de quem' é um objeto que está em foco, ou de quem é uma idéia colaborativa. A participação do indivíduo numa resolução de problemas, ou numa comunicação, já envolve um processo além do nível individual. Se beneficiar do pensamento compartilhado não envolve "tomar" alguma coisa de um modelo extemo. Ao invés disso, no processo de participação de uma atividade social, o indivíduo jáfunciona com uma compreensão compartilhada. O uso posteriordesta compreensão não é o mesmo que foi construído conjuntamente; implica na apropriação da atividade compartilhada através da qual cada indivíduo reflete a sua compreensão deacordo com o seu envolvimento na atividade. (Rogoff, 1990, p. 195)

Além disto, a questão que se coloca é se o que é intemalizado permanece tal qual era no mundo exterior, ou se existe uma transformação como resultado da intemalização. Para Rogoff (1990, p. 197), o mundo social (asinformações, habilidades, etc.) "não é transmitido mas transformado..." A autora destaca que o limite entre os tempos ( o 'antes' e o 'depois'), além da separação entre a mente individual e o mundo social extemo, possibilita a concepção de transmissão - e não transformação - de informações (embora esta, a transmissão, nunca tenha sido uma proposta de Vygotsky!), permitindo o uso da metáfora do 'depósito de informações' (storage). Esta metáfora implica que o indivíduo disponha de parte das informações estocadas na memónia (passado), transmita estas informações no presente para que possam ser compartilhadas ou não, e, finalmente, intemalize as novas informações advindas da relação presente, no futuro.

Para Valsiner (2000), no entanto, a comunicação, envolvendo um processo tanto de extemalização como de intemalização, é considerada como um processo de transformação de informação no plano semiótico:

... o processo comunicativo envolve a construção e o uso de signos - eneste sentido é um processo semiótico. Um insight particular (X) de uma pessoa A se toma extemalizado através dela na forma de uma mensagem semioticamente codificada (X'), e assim fica publicamente disponível para outraspessoas. Entre estas pessoas, $X^{\prime}$ pode ser ignorada por muitas, neutralizada ou nidiculanizada poralgumas, elevadas a sénio por umas poucas. Entre estas últimas, X' pode se transformarno processo de intemalização e se tomardiferente (e.g., a pessoa B transformaX'em Y), seguida da extemalização construtiva de Y dentro de uma nova forma de disponibilização pública ( $\left.Y^{\prime}\right)$, a qual, porsua vez, é a mensagem para A e outras pessoas. (Valsiner, 2000, p. 11)

Para Rogoff (1990, 1998), o foco recai na transformação que ocome na participaçãoguiada numa atividade social. Esta transformação refere-se ao papel do sujeito na atividade e em sua compreensão da atividade. Isso não é igual a conceberuma diferença no desenvolvimento do indivíduo apenas como resultante da atividade. A diferença - 0 desenvolvimento - estárelacionado à mudança doindivíduo, dastelaçóesedaatividadedentrodeumacomunidadehistoricamente consituída.

A questão da transferência de um conhecimento prévio para uma situação presente que implica em algo intemalizado pelo sujeito, passa a ser analisada focalizando a participação da pessoa numa deteminada atividade (Lave, 1988, 1991) e como esta participação se relaciona com a sua participação em outra atividade. Para a autora, não são os objetos ou conteúdos (conceitos, signos, etc.) que são transferidos de uma situação a outra "como se eles existissem isolados na cabeça” (Rogoff, 1998, p. 691). O termo apropriação é proposto, então, para significar um processo constante de mobilização dos conteúdos, dos sujeitos, das relações e dos artefatos culturais que estão incluídos em uma atividade específica. Infere-se, assim, que, o que é intemalizado é a própria atividade como um todo que permitirá ao sujeito a sua participação em atividade similar posterior.

Utilizando o temo apropriação participatória, Rogoff (1995) define um processo que

... se refere a como os indivíduos mudam através do seu envolvimento em uma ou outra atividade, tomando-se preparadospara um envolvimento subsequente em atividades relacionadas. Com a participação guiada como o processo interpessoal através do qual as pessoas são envolvidas na atividade sociocultural, a apropriaçãoparticipatónia éo processo pessoal pelo qual, através do compromisso em uma atividade, os indivíduos mudam e controlam uma situação postenior de maneira preparada pela própria participação na situação prévia. Esse éum processo de apropriação e não de aquisição ... (Rogoff, 1995, p. 142)

Segundo a autora, existem três usos possíveis para o conceito de apropriação. $\mathrm{O}$ primeiro considera apenas o transporte de uma informação de fora para dentro; 0 segundo concebe o processo como "algo extemo [que] 
é importado e transformado para se adequarao propósito do novo possuidor" em momentos sucessivos do processo. No terceiro uso, no dizer da autora, a "apropriação participatória é um processo de transfomação, e não um requisito para a transformação" (Rogoff, 1995, p. 152, grifos nossos).

Apesardaapropriaçãoparticipatónia seruma atividade do sujeito, ela envolve um processo no qual estão incluídas as relaçõesinterpessoais e os artefatos culturais; enfim, envolve toda a atividade sociocultural. A caracterização desta mudança requer o estudo "dos processos", "das abordagens", das "habilidades e conhecimentos" no 'todo' indivisível que caractenza a unidade de análise de Rogoff (1991, pp. 362-363).

Desta forma, pode-se concluir, a diferença marcante e a divergência no uso do conceito de intemalização encontra-se e sustenta-se no fato deste termo suporuma separação entre o intemo e o extemo, entre o individual e o social. Ao contrário, o conceito de apropriação, como entendido pela autora, implica apenas numa inclusão fusionada (Lyra \& Valsiner, 1998) e não numa separação inclusiva (Valsiner, 1997, 2000; Valsiner \& Van Der Veer, 2000) que permite o reaparecimento do sujeito em relação, na psicologia.

Os estudos realizados por Rogoff não exploram em profundidade o conceito de apropriação participatória. Todavia, eles são um esforço para demonstrar o uso da unidade de análise inclusiva, por ela proposta, que inclui o indivíduo, as relações interpessoais e a comunidade/ instituição na qual a atividade sociocultural tem lugar. Destacam, também, como a participação guiada em atividades socioculturais propicia o desenvolvimento da capacidade de tomar decisões cada vez mais lógicas, econômicas e adequadas às situações propostas.

\section{Metodologia e Estudos Realizados}

O trabalho da autora abarca estudos etnográficos, utilização de videografia, entrevistas e outras formas de observação, bem como trabalhos em laboratónio. Estes trabalhos em laboratório têm o objetivo de aprofundar questões que são evocadas nos estudos etnográficos da vida diánia, ou vice-versa.

As questões que a autora coloca estão relacionadas com a compreensão de como participantes de uma atividade e a comunidade na qual a atividade tem lugar, mutuamente constituem esta atividade, considerando esta constituição do ponto de vista histórico. Rogoff e colaboradores (no prelo) realizam um interessante e complexo trabalho de análise metodológica, mostrando a inter-relação entre o sujeito, as relações interpessoais e a instituição em fases sucessivas na constituição da atividade de vendas de biscoitos pela comunidade de escoteiras, Girl Scout Cookie, historicamente conhecida e famosa nos EUA - desde a preparação dos biscoitos até o roteiro de entrega domiciliar.

A questão de interesse, e que passaremos a argumentar utilizando-nos dos argumentos da própria autora, é como ela responde à questão de como a mente se desenvolve socialmente. Se a mente não se toma social, mas se sofistica socialmente, como as pessoas usam habilidades que trazem ao nascer e situações passadas para se adaptara novas situações? A autora dá um exemplo de uma situação de laboratónio, onde as mães pedem às crianças que façam a classificação de itens (amumação dos itens nos locais apropriados da cozinha), tal qual a classificação da cozinha de suas casas.

Esta compreensão entre as duas situações não ocome na cabeça do sujeito, mas na comunicação intersubjetiva das pessoas envolvidas na situação. A capacidade para esta intersubjetividade é inata e aparece na crescente habilidade da criança de entender a expressão facial não verbal da mãe, bem como na entonação de suas palavras. Esta intersubjetividade se sofistica no desenvolvimento da função lingüística na comunicação. A intersubjetividade é responsável pela mudança no desenvolvimento, que se dá através do compartilhamento do significado. A linguagem possibilita tal compartilhamento e o desprendimento do significado da situação presente.

A questão do caráter social desta intersubjetividade inata é questionada através da dúvida sobre a intencionalidade do ato da criança na comunicação. No entanto, mais importante para a autora, é a função comunicativa que efetivamente têm os gestose "palavras" primánias para serem considerados sociais. Ou seja, se a criança tem a intenção de deliberaruma ação porparte do adulto não é tão importante quanto o fato dela responder de forma eficaz à intenção do adulto na comunicação. Esta função comunicativa que têm os gestos e "palavras" da criança pode não provir de uma intencionalidade deliberada desta, mas a sua resposta eficaz justifica o fenômeno comunicacional como um fenômeno social proporcionado porestamesmacapacidade inata de intersubjetividade (Rogoff, 1990).

Esta intersubjetividade se apresenta como modelos diferentes de interação em diferentes comunidades. A criança compartilha o mundo da comunidade onde se insere a partir do modelo de interação dentro da comunidade, mesmo que este não tenha por objetivo ensiná-la. Em 1991, Rogoff relata várias pesquisas realizadas com a classe média americana. O objetivo é verificarcomo a participação guiada promovea apropriação da habilidade de planejar roteiros imaginánios de viagens espaciais numa situação virtual. 
Uma destas pesquisas consistiu em separar grupos de crianças de 4 a 5 anos e de 6 a 9 anos que lidavam com 3 diferentes situações: 1 - com parceiros previamente instruídos na ação colaborativa; 2 - com parceiros não instruídos; 3 - com adultos que supostamente são mais instruídos. Foi realizado um pós-teste com a criança sozinha para verificar se ela havia apropriado as habilidades necessárias à realização da tarefa.

$\mathrm{O}$ teste consistia em mostrar à criança um mapa de uma cidade imaginária. O objetivo era encontrar um roteiro que economizasse gasolina, partindo da escola e passando pelas lojas, a fim de adquinir os itens propostos para compra que a escola precisava para realizar uma festa. Cada participante tinha uma lista de cinco itens. Para a eficiência do roteiro, era necessária a coordenação da ordem de passagem pelas lojas, bem como, saber em quais lojas poderiam ser comprados tais e/ ou tais itens, conforme o mapa apresentado pelos participantes. Para encontrar um roteiro ideal, era necessário fazer um planejamento incorporando as lojas.

A performanceda criança na tarefa foi comparada a sua performanceno pós-teste. A análise consistia na quantificação necessánia ou desnecessánia de lojas no roteiro imaginánio proposto pelos participantes. Os resultados mostraram que as crianças se saíam melhor no pós-teste quando trabalhavam com adultos, do que quando trabalhavam com aquelas previamente instruídas, e que se saíam melhor com crianças treinadas, do que com crianças não treinadas. O motivo da diferença entre os dois primeiros casos é a explicitação oferecida pelo adulto sobre a tarefa.

Em outra expenência no mesmo estilo, com diferente design metodológico, a autora pede àscriançasque planejem uma rotina através de lojas para a compra de cinco itens, sem poder andar para trás. Nesta experiência as crianças trabalharam em duplas com outras crianças, com adultos, ou sozinhas. Os resultados mostraram que não havia diferença de performancenas três situações, a não serquando havia um compartilhamento de decisões entre ambos os parceiros.

A conclusão a que a autora chega éque o fato de trabalhar em dupla não garante por si só o desenvolvimento da intersubjetividade. Para que isso ocorra, é necessánia uma participaçãoguiada na qual a criança realizaum envolvimento ativo de observação e desenvolve a habilidade de tomar decisões. Destaforma, esta participaçãoguiada estápemitindo a apropriação da habilidade de tomar decisão através do trabalho conjunto. Esta participação guiada tem o objetivo de transferir responsabilidades para a criança, a fim de permitir o momento posterior de independência da criança em relação ao colaborador. A intersubjetividade não se desenvolve pelo fato de a criança estar em contato com o meio, mas depende da qualidade das relações estabelecidas com ele.

Em 1997, Rogoff e Toma analisam o processo intersubjetivo procurando entendero modelo relacional que permite 0 envolvimento eficaz na realização da tarefa. Qualquer modelo dado produz uma compreensão mútua, que não é idêntica entre os parceiros, mas permite um substrato comum para a exploração de aspectos diferentes do fenômeno relacionado à atividade. Este processo é analisado explorando-se regularidades estruturais do suporte dado à criança na participaçãoguiada.

Foram analisadas comunidades como a classe média americana e os Maias Guatemaltecos. No primeiro caso, o suporte dado à criança é estruturado através da transmissão da informação em relações diádicas. No segundo caso , a aprendizagem da criança está relacionada ao que a autora chama de uma atividade multiparte que se desenvolve em grupo. No primeiro caso, a relação é mais dirigida e há uma tentativa de trazer a criança para uma atividade criada especialmente para a transmissão de lições oportunistas (aprender palavras novas, por exemplo). No segundo caso, a linguagem utilizada com as crianças sugere ações e procura prover informações no curso da atividade da qual outras pessoas participam. A criança se engaja na atividade e se relaciona com vánias pessoas. $\mathrm{O}$ adulto provê uma breve orientação para a realização da atividade, assistindo a criança quando necessánio.

A diferença é que o papel do adulto no primeiro caso é o de organizar a aprendizagem da criança, através da motivação para o recebimento de instruçõespara a realização da tarefa. No segundo caso, o papel do adulto é o de assistir a criança, a fim de mantê-la integrada na atividade em grupo. As relações que se estabelecem com a criança são duais, no primeiro caso, e comunitánias no segundo.

Chavajay e Rogoff (2002) mostraram que o sistema escolarinfluencia nesta direcionalidade do suporte dado à criança dentro da comunidade. Eles observaram que mães que passaram pela escola na comunidade Maia da Guatemala e que tinham o objetivo de ver os filhos escolarizados, passavam a agir com base no modelo de transmissão de informação, como que preparando a criança para o ensino escolar. A conclusão a que chegaram é que a participaçãoguiada éuniversal, mas difere de cultura para cultura. Ela estrutura a atividade da criança. Ela difere pela lição a ser aprendida pela criança; pelo modelo de participação e comunicação; pela habilidade e valores que são promovidos de acordo com o objetivo da comunidade.

Desta forma, com base nestes trabalhos, pode-se argumentarquea autora mostra como a participaçãoguiada 
desenvolve a intersubjetividade que se apresenta como modelos específicos característicos de uma comunidade, levando à apropriação de habilidades e informações que remetem a habilidades e informações que foram produzidas de diferentes maneiras em situações passadas. É através desta apropriação, possível pela participação guiada, que a mente se desenvolve socialmente, entendido esse social, não como algo que vem de fora (abordagem da influência cultural), mas como o meio no qual a mente, social ao nascer, se une indissoluvelmente em diferentes atividades socioculturais. Ou seja, a mente é social e se desenvolve socialmente (ela não nasce desenvolvida, mas social) e é esta mente vista como relação mente/cultura; como uma unidade mutuamente constitutiva, focalizada metodologicamente através da atividade sociocultural, que se desenvolve constantemente.

O trabalho da autora parece estar mais ligado a mostrar como a participação guiada é importante no desenvolvimento da mente social. O conceito de apropriação não é explorado per se, nem se percebe nestes trabalhos a emergência do sujeito advinda deste processo de apropriação. Ou seja, como o sujeito se apropria do conhecimento numa atividade?Ou por outra, como 0 sujeito emerge em singularidade neste processo de apropriação?A ênfase está centrada na participação guiada como responsável pela apropriação, e não na exploração deste processo em si. Desta forma, tal como foi explicitado anteriormente, a proposta de Rogoff afirma que o polo diferenciado da subjetividade (individual) surge na fusão com o ambiente cultural (Lyra \& Valsiner, 1998).

\section{A Contribuição de Valsiner: 0 Resgate do Sujeito}

Valsiner (1997) é um exemplo de um teórico que axiomaticamente assume a centralidade da pessoa como um agente autônomo dentro de um mundo organizado culturalmente. A autonomia pessoal e a individuação são, elas próprias, culturalmente constituídas (através do processo de intemalização/extemalização). Disso decome que as pessoas e o contexto sociocultural no qual elas participam são culturais, embora diferentes. (Budwig, Valsiner \& Bamberg, 1998, p. 8)

Esta citação parece esclarecer uma das principais contribuições de Valsiner para a Psicologia Cultural, a partir de uma abordagem sociocultural. Para este autor (Valsiner, 1997, 2000), o sujeito é concebido como uma realidade axiomática. $\mathrm{O}$ contexto cultural é visto como desempenhando um papel determinante, porém relativizado. $O$ contexto e o sujeito são culturais, e está na natureza da relação entre ambos a compreensão do processo de desenvolvimento desta autonomia do sujeito. A mediação semiótica desempenha papel-chave na troca de informações entre o sujeito e o meio (ambos culturais), através do processo constante de internalização/ extemalização.

Este processo de intemalização/extemalização possibilita, ao mesmo tempo, momentos nos quais se constata uma marcada diferenciação do sujeito (e da cultura), bem como momentos de indiferenciação (ver, excelente ilustração na análise do caso de Aurora em Oliveira \& Valsiner, 1997, e em Lawrence, Benedikt\& Valsiner, 1992). Desta forma, o papel do contexto e da cultura é relativizado no trabalho de Valsiner $(1995,2000)$ através do conceito de separacão inclusiva, na qual a atividade semiótica desempenha um papel, tanto na diferenciação, como na autonomia do sujeito imerso nesta cultura.

A questão da subsistência e autonomia do sujeito, em sua relação com a cultura, é colocada não como dada a priori, mas como resultante desta atividade semiótica que possibilita o ato criativo e transformador sujeito e da cultura, marcado, o sujeito, poruma constante relação de intemalizacão/extemalizacão. Se a realidade do sujeito é dada a priori como axiomática, sua diferenciação se mostra como conseqüência do desenvolvimento de sua autonomia (através da atividade imersiva) ao longo de sua subsistência.

$\mathrm{Na}$ mesma direção, mas focalizando mais especificamente a linguagem, numa perspectiva ligada à psicologia lingüística, Bhatia afirma que a distinção entre ambos o sujeito e a cultura é "criada através da fala e é um 'produto' da prática lingüística” (Bhatia, 1998, p. 31). Baseada em Hanks (1996), a autora afirma que não se pode compreender a linguagem do sujeito como isolada do contexto, e nesta relação sujeito/contexto sociocultural, o sujeito aparece através da tensão entre a produção criativae a produção rotinizada considerada como uma reprodução.

Este processo de produção criativa nosremete àsidéias de Bakhtin (1981), no sentido de abordar a questão de como uma "linguagem social" (cultural) se toma uma "voz individual" (Wertsch, 1991).

Visto desta maneira, a relação sujeito/cultura implica na análise dos limites e possibilidades que estão imbricados na significação da palavra. A mente vista como um ato de significação (Bakhtin, 1995) requeruma consideração mais apropriada sobre o caráter eminentemente social da palavra, enquanto possibilidade de comunicação. Ao mesmo tempo, ela própria (a palavra) permite que o sujeito possa emergir em singularidade, como, também, em diferenciações progressivas. Ao nosso ver, a mente compreendida desta maneira implica numa fusionalidade incontestável, mas, ao mesmo tempo, numa possibilidade de superação em atos criativos. Trata-se de um dialogismo 
dialético no qual a fusão inclui a diferenciação (Emerson, 1997; Holquist, 1990). A luta pelo "resgate do sujeito" em sua relação fusionada com a atividade/contexto/meio social recebe o seu caráter de existência na diferenciação discursiva do sujeito em interação (Valsiner \& Van DerVeer, 2000).

\section{O Ato Criativo do Sujeito na Comunicação segundoValsiner}

Considerando o fenômeno da mudança que caracteriza todo desenvolvimento, a diferença entre as concepções de Rogoffe Valsiner se evidencia no discurso científico destes dois autores:

Compreendercomo as pessoas se desenvolvem [grifos nossos], isto é, como elas mudam na sua participação em atividades socioculturais, requerque se dinja a atenção às mudançasna atividade, à mudança na responsabilidade e papeldas pessoas, e em como a participação das pessoas está relacionada a se tornar membro de uma comunidade, com instituições, tecnologias e definições, de forma inteligente. (Rogoff, 1998, p. 729)

Porque todo processo de desenvolvimento tem seu estático limite exterior, estabelecido através do contexto em que o organismo se desenvolve, e pelo estado do próprio organismo, a pesquisa sobre 0 aspecto dinâmico do desenvolvimento futuro do organismo pode explicitamente considerar estes limites ou fronteiras estáticas (temporánas) como a base na qual o desenvolvimento tem lugar. (Valsiner, 1997, p. 27)

Comparando-se os fragmentos dos dois discursos, percebe-se claramente uma diferença relativa à noção de que existe um limite entre o sujeito e o ambiente (cultural) extemo, para Valsiner, epara Rogoff, o processo de mudança parece fundiro sujeito e as atividades socioculturais com as quais este sujeito está envolvido, por deixar em aberto a questão da diferenciação e pemanência do sujeito.

Este limite, refenido por Valsiner (1997), diz respeito à necessidade da estabilidade na mudança que caracteniza a existência de um sujeito diferenciado do ambiente sociocultural, no qual ele se desenvolve e está imemediavelmenteincluído.

Segundo Valsiner (1994, 2000), a estabilidade do sujeito - e o desenvolvimento deste sujeito - deve servista à luz da imeversibilidade do tempo. Nesta perspectiva, um objeto $\mathrm{X}$ se toma $\mathrm{Y}$ e este mesmo objeto $\mathrm{X}$ permanece como X. No primeiro caso, o autor enfatiza a transformação, a mudança. No segundo, a permanência das caracteństicas (de X), que permite, porsua vez, a autonomia de X face à mudança. Masem que consiste esta pemanência eautonomia?
A ênfase na centralidade, diferenciação e autonomia do sujeito requer o estudo da sua permanência face às mudanças inerentes a um tempo imeversível. A inovação', ou o 'ato criativo', decorre desta irreversibilidade do tempo que faz com que o sujeito precise enfrentar um tempo presente que, constantemente, se toma futuro (desconhecido). Todavia, a 'novação', ou o 'ato criativo', decorre, também, da permanência do sujeito no tempo. Desta forma, só se pode falar em mudança quando se tem em mente a permanência de um sujeito diferenciado.

Para Valsiner (2000), esta permanência do sujeito remete a uma estabilidade temporal, que é, por fim, uma ilusão claramente expressa no trecho que se segue:

... em meu esforço para sentirestabilidade eu uso uma classe de experiências similares $\left(A^{\prime}, A^{\prime \prime}, A^{\prime \prime}\right)$ como base para minha expectativa que o próximo evento de uma espécie similar, no futuro, possa se suceder de maneira similaràqueles que eu reconstrui (no presente) e que ocomeram no passado. O ser humano, precisamente porque seu futuro é indeterminado, usa instrumentos psicológicos para criar imagens de estabilidade para o futuro. Na construção psicológica do processo, eles superam amaneiraúnica de cadavivênciaatravés da experiência e tentam construirum curso de eventos previsíveis, recorrentes e sabidos. Isto é uma construção psicológica ilusónia queébaseadananecessidade da adaptação dentro de um meio ambiente constantemente em mudança. Isto é uma enome ilusão necessána para a vida psicológica humana. Ainda isso faz com que os indivíduos fiquem 'cegos' para exatamente aquelesaspectos de suasrelações com o meio ambiente que toma o desenvolvimento possível - isto é, a novidade. (Valsiner, 2000, pp. 17-18)

Neste sentido, é uma ilusão achar que o presente é uma repetição do passado para o sujeito singular que constrói o presente. A diferença entre o discurso de Rogoff e a perspectiva de Valsiner acerca da estabilidade no tempo - que permite a diferenciação e autonomia do sujeito - trata-se, para Valsiner, de uma ilusão (ou de uma possível estratégia metodológica) - a ilusão da permanência no tempo irreversível. Esta concepção de Valsineré coerente com o conceito de abdução proposto por Peirce (1935) que propõe a existência de uma lógica diversa, nem dedutiva nem indutiva, para explicar o processo de criação de hipóteses (voltadas, portanto, para o futuro) que estão fundamentadas na história passada e no momento presente.

Propomos que o que existe de permanente é a consciência histórica da mudança face ao tempo irreversível que obriga ao sujeito a enfrentar o futuro que é sempre 'novo'. Este sujeito existe na rede de interseções na qual ele se constitui, constituindo, também, a 
comunidade (cultura) onde se engaja, de forma mútua e contínua. Essa consciência histórica da mudança é uma realidade incontestável porque é ela que fomece ao sujeito as bases para o 'ato criativo' que o sujeito enfrenta no futuro desconhecido. Todavia, está na capacidade semiótica do sujeito a possibilidade de viver uma estabilidade, mesmo que ilusónia, que permite a existência de um sujeito semiótico diferenciado, singulare autônomo em meio a sua própria imersão sociohistórica cultural.

\section{Considerações Finais}

Este trabalho analisou a perspectiva sociocultural de Rogoff em relação à proposta da autora de uma unidade de análise que inclua o sujeito, as relações intersubjetivas (cuja capacidade a criança já traz ao nascer), os artefatos culturais e simbólicos e a comunidade/instituição em que atua, como intrinsecamente compondo num 'todo' indivisível. O que pode ser apreendido do seu acervo teórico é que a mente é social por natureza e não pode serpensada como uma mente 'que se toma social' sob a influência do meio ambiente. Isto não significa, no entanto, dizer que não haja transformações relativas ao desenvolvimento. Todo o trabalho da autora busca mostrar como a unidade de análise proposta dá conta do estudo e compreensão do processo de desenvolvimento da criança.

Todavia, a análise do conceito de participação guiada proposto por Rogoff (1991), como explicando o mecanismo ou processo através do qual o sujeito se diferencia e se constitui, sugere que o polo diferenciado da subjetividade (individual) surge em decomência da fusão com o ambiente cultural (Lyra \& Valsiner, 1998). Desta forma, a singularidade e autonomia do sujeito tanto não ficam claramente delimitadas, como não possuem uma consideração específica a partir da perspectiva da referida autora. Dito de outra forma, o conceito de apropriação participatónia, propriamente dito, que dá sentido à participação guiada, não é explorado em si como um processo que permite à pessoa o desenvolvimento da sua autonomia imersiva e diferenciação participativas.

Procurando resgatar a singularidade do sujeito, sua autonomia, foi feito uso da concepção de Valsiner(1986), sobretudo no tocante a sua proposta acerca do processo de desenvolvimento como envolvendo um limite entre o sujeito e a cultura que não é uma fusão nem um limite intransponível. Trata-se de uma separação inclusiva, na qual a singularidade do sujeito pode emergir e se desenvolver, em meio ao emaranhado das relações socioculturais. Ainda, segundo Valsiner(1986, 1994), o sujeito - sua diferenciação, autonomia e singularidade - é reconhecido no 'ato criativo' que ocome como decomência da imeversibilidade do tempo e da necessidade do sujeito enfrentar o futuro, sempre incerto. Diante deste impasse, o sujeito cria uma ilusão de estabilidade no tempo que decorre tanto da historia passada como do momento presente. Neste 'ato criativo', no qual o sujeito se manifesta, estão presentes tanto o passado, como o presente e o futuro.

Propusemos, neste trabalho, uma síntese entre a caracterização da atividade como um 'todo' e a caracterização do indivíduo como 'o' elemento responsável pela suaconstrução. Esta síntese, de uma parte, faz uso daunidade de análise inclusiva proposta por Rogoff (1990; Rogoff \& cols., no prelo) que dá conta do indivíduo, das relações intersubjetivas, dos artefatos culturais, enfim, da atividade dentro de uma comunidade historicamente constituída. De outra parte, utilizamos a concepção do sujeito singular (separado enquanto realidade axiomática e imerso enquanto autonomia) manifesto no 'ato criativo' diante de um tempo irreversível (Valsiner, 1994). Este sujeito, único e diferenciado, é um sujeito semiótico, concebido como eminentemente inserido na cultura através e sobretudo da comunicação interpessoal.

\section{Referências}

Bakhtin, M. N. (1981). Thedialogical imagination: Four essaysby M. M. Bakhtin (M. Holquist, Org.). Austin: University of Texas Press.

Bakhtin, M. N. (1995). Marxismo efilosofia da linguagem (M. Lahud., Y. F. Vieira \& cols., Trad.) (7ª ed.). São Paulo, SP: Hucitec.

Bateson, G. (1972). Stepstoan ecology of mind: A revolutionary approach to man's understanding of himself. New York: Ballantine.

Bhatia, S. (1998). Towards a synthesis of community and communicative practices. ClarkWorkingPaperson Developmental Psychology, 1, 26-33.

Bruner, J. (1990). Acts of meaning. Cambridge, MA: Harvard University Press.

Bruner, J. (1997). Celebrating divergence: Piaget and Vygotsky. Human Development, 40, 63-73.

Budwig, N., Valsiner, J. \& Bamberg, M. (1998). The inter-disciplinary study of human development ClarkWorking Paperson Developmental Psychology, 1, 1-16.

Carraher, T. N., Carraher, D. W. \& Schliemann, A. D. (Orgs.) (1985). Mathematics in the streets and in schools. British Journal of Developmental Psychology, 3, 21-29.

Chavajay, P. \& Rogoff, B. (2002). Schooling and traditional collaborative social organization of problem solving by Mayan mothers and children. Developmental Psychology, 38, 55-66.

Cole, M. \& Wertsch, J. V. (1996). Beyond the individual-social antonomy in discussion of Piaget and Vygotsky. Human Development, 39(5), 250256.

Emerson, C. (1997). The first hundred years of Mikhail Bakhtin. Pinceton, NJ: Princeton University Press.

Hanks, W. F. (1996). Languageand communicativepractices Boulder, CO:Westview Press.

Holquist, M. (1990). Dialogism: Bakhtin and hisworld. London: Routledge.

Lave,J. (1988). Cognition in practice: Mind, mathematicsand culturein everydaylife. Cambridge, UK: Cambridge University Press. 
Lave, J. (1991). Situating learning in communities of practice. Em L B. Resnick, J. M. Levine \& S. D. Teasley (Orgs.), Perspectiveson socially shared cognition (pp. 63-82). Washington, DC: American Psychological Association.

Lawrence, J. A, Benedikt, R. \& Valsiner, J. (1992). Homeless in the mind: A case history of personal life in and out a close orthodox community. Journal of Social Distressand theHomeless, 1(2), 157-176

Lerman, S. (1996). Intersubjectivity in mathematics learning: A challenge to the radical constructivist paradigm?Journal for Research in Mathematics Education, 27(2), 133-150.

Lyra, M. C. D. P. \& Valsiner, J. (1998). Introduction: Process approach in sociogenesis. Construction of psychological processes in interpersonal communication. Em M. C. D. P Lyra \& J. Valsiner (Orgs.), Child developmentwithin culturally structured environment(Vol. 4, pp. 1-11). Stamford, Connecticut: Alex.

Oliveira, Z. M. R., \& Valsiner, J. (1997). Play and imagination: The psychological construction of novelty. Em A. Fogel, M. C. D. P. Lyra \& J. Valsiner(Orgs.), Dynamicsand indeterminism in developmental and social processes (pp. 119-133). Mahwah, NJ: Enbaum.

Peirce, S. (1935). Collected papers of Charles Peirce (Vol. 6). Cambridge, MA: Harvard University Press.

Piaget, J. (1964). Six études depsychologie. Genève: Gonthier.

Piaget, J. (1971). O nascimento da inteligência na criança (A. Cabral, Trad.). Rio de Janeiro, RJ: Zahar.

Piaget, J. \& Inhelder, B. (1966). La psychologiedel'enfant. Panis: P.U.F.

Rogoff, B. (1990). Apprenticeshipin thinking. New York: Oxford

Rogoff, B. (1991). Social interactions as apprenticeship in thinking: Guided participation in spatial planning. Em L.B. Resnick, J. M. Levine \& S. D. Teasley. (Orgs.), Perspectives on socially shared cognition. (pp. 349-364). Washington, DC: American Psychological Association.

Rogoff, B. (1995). Observing sociocultural activity on three planes: Participatory appropriation, guided participation, and apprenticeship. Em J.V. Wertsch, P. Del Rio \&A. Alvarez (Orgs.), Sociocultural studiesofmind (pp. 139-163). Cambridge, UK: Cambridge Universtity Press.

Rogoff, B. (1998). Cognition as a collaborative process. Em W. Damon, D. Kuhn \& R. S. Siegler (Orgs.), Handbook of child psychology: Cognition, perception and language, 2, 679-744. New York: Wiley.

Rogoff, B. \& Toma, C. (1997). Shared thinking community and institutional vanations. DiscourseProcesses, 23, 471-497.
Rogoff, B., Topping, K., Baker-Sennett, J., \& Lacasa, P. (no prelo). Mutual contributions of individual, partners, and institutions; planning to remember in Girl Scout Cookie sales. Social Development.

Tomasello, M. (1999). The cultural origins of human cognition. Cambridge, MA: Harvard University Press.

Valsiner, J. (1986). Where is the individual subject in scientific psychology? Em J. Valsiner(Org.), Theindividual subjectand scientific psychology (pp. 114). New York: Plenum Press.

Valsiner, J. (1994). Irreversibility of time and the construction of historical developmental psychology. Mind, Culture, and Activity, 1, 2-25.

Valsiner, J. (1995). Editorial: Culture and Psychology. Cultureand Psychology, 1, 5-10.

Valsiner, J. (1997). Cultureand the development of children 'saction. New York: John Wiley \& Sons.

Valsiner, J. (2000). Cultureand human development: An introduction. London: Sage.

Valsiner, J. \& Van DerVeer, R (2000). Thesocial mind: Construction of theidea. Cambridge, UK: Cambridge University Press.

Vygotsky, L S. (1978). Mind in society: Thedevelopmentof higher psychological processes. Cambridge, MA: Harvard University Press.

Vygotsky, L S. (1987). Thinking and speech. Em R. W. Rieber \& A. S. Carton. (Orgs.), The collected works of L S. Vygotsky (N. Minick, Trad.). New York: Plenum Press.

Vygotsky, L S. (2001). A construção do pensamento eda linguagem (P. Bezerra, Trad.). São Paulo, SP: Martins Fontes.

Wertsch, J. V. (1991). A Sociocultural approach to socially shared cognition. Em L B. Resnick, J. M. Levine, \& S. D. Teasley (Orgs.), Perspectives on socially shared cognition (pp. 85-100). Washington, DC: American Psychological Association.

Wertsch, J. V. (1998). Mind asaction. New York: Oxford.

\author{
Sobre as autoras \\ Eveline Vieira Costa é Doutoranda do Curso de Pós-graduação em Psicologia da Universidade \\ Federal de Pemambuco. \\ Maria C.D.P. Lyraé Doutora em Psicologia e Professora do curso de Pós-graduação em Psicologia \\ da Universidade Federal de Pemambuco, Pesquisadora do CNPq.
}

Recebido: 31/10/2001

1' Revisão:02/01/2002

Última Revisão: 21/06/2002

AceiteFinal: 26/06/2002 